\title{
An Investigation into the Effect of Tutorial Lectures given by the Teaching Assistant on Student's Academic Performance in Undergraduate Engineering Classes
}

\author{
Taissir Y. Elganimi \\ Electrical and Electronic Engineering Department \\ University of Tripoli, Libya
}

\begin{abstract}
In this study, the impact of tutorial lectures given by the teaching assistant on the academic achievement of undergraduate engineering students was investigated based on student's total scores. Student's performance was analyzed in a specific course for nine classes in Electrical and Electronic Engineering Department at University of TripoliLibya. Data were analyzed using regression and correlation statistical tools. The results of the analysis revealed a positive correlation between tutorial lectures and student's performance in the examination. In other words, the statistics over five groups with tutorial lectures given by a teaching assistant demonstrated a significant effect of a weekly one hour tutorial lecture on the student's total scores. The impact of the whole number of students in the class on the student's achievement was examined as well, and it showed that the number of succeeded students with inversely proportional to the whole number of students in the class. Finally, it was also found that gender has a significant effect on the student's performance, and male students performed better than their female counterparts. The EXCEL was used for the elaboration of data.
\end{abstract}

\section{Introduction}

This paper adds weight to the existing body of evidence. It reports the results of research into the effect of tutorial lectures attendance given by the teaching assistant on the academic performance of students in a specific course called "Basic Electronic Circuits" in Electrical and Electronic Engineering Department at University of Tripoli-Libya. The course was studied by comparing the performance of undergraduate engineering students in nine groups with the same lecturer in deferent semesters and different groups; four groups in four semesters were without tutorial lectures, and the other five groups were with tutorial lectures given by the same teaching assistant.

Typically, undergraduate lectures in the courses in Electrical and Electronic Engineering Department at University of Tripoli consisting of 2.5-3 hours of classes given by the instructor of the course every week for the duration of 14 to 16 weeks in each semester, and a weekly one-hour tutorial lecture given by the teaching assistant.

Unlike most of the other studies, which use crosssection data on attendance and performance, this study is based on panel data, which allow us to control for unobserved heterogeneity among students. Such heterogeneity arises because of different levels of motivation, intelligence, prior learning, and time-management skills.

When performing statistical analysis on a set of data, both the mean and standard deviation are helpful values to calculate. The mean (also known as average) is an estimate of where the middle of a set of data is, while the standard deviation is the average distance between the actual data and the mean.

In this study, the student performance for the "Basic Electronic Circuits" subject (course code: EE219) is presented with the correlation between the student grades in five groups with tutorial lectures given by the teaching assistant ${ }^{1}$ and the total scores for another students received in the same course with the same instructor in four groups without tutorial lectures given by a teaching assistant. The topics and the evaluation process for student's performance in this subject were the same in the nine classes, and the total score is calculated from:

1. Some homework assignments.

2. Some quizzes.

3. Two midterm exams.

4. And a final examination.

For the four groups which didn't have any tutorial lectures given by a teaching assistant, there were 58

\footnotetext{
${ }^{1}$ The teaching assistant who gave the tutorial lectures in the mentioned course is the author of this paper.

students in Spring 2008 (group B), 44 students in Spring 2009 (group A), 39 students in Spring 2010 (group B), and 50 students in Fall 2010 (group C). While in the five groups which had tutorial lectures given by the teaching assistant, there were 45 students in Spring 2012 (group A), 43 students in Spring 2012 (group B), 22 students in Summer 2012, 74 students in Fall 2012 (group A), and 50 students in Fall 2012 (group B).
} 
Like other studies, this study finds strong evidence that performance is linked to attendance of tutorial lectures given by teaching assistants.

\section{Who is the teaching assistant?}

Generally, the teaching assistant in the universities is a graduate student has a bachelor's degree, and works as a demonstrator to the students, or assistant to the professor or the instructor of the course.

Some teaching assistants work as lab demonstrators and helping the students in the laboratory, some of them work as tutorial leaders by giving tutorial lectures for undergraduate students in undergraduate courses as at University of Tripoli, and some of them work as a marker by marking exams, home-work assignments, or papers. But the main function of the teaching assistant in faculty of engineering at University of Tripoli-Libya is giving the tutorial lectures for students in small groups.

Indeed, as many introductory courses become larger and more impersonal, the teaching assistant often serves as a key link between the undergraduate students and the professor or the instructor of the course. In general, they have a tremendous influence on the quality of education when they teaching a class, leading discussions, marking exams or papers, or tutoring students in tutorial lectures [1]. In addition, teaching assistants often provide a friendly face for many students, and they work as students, as teachers, as assistants, and as an advisor to the students.

\section{What are tutorial lectures?}

In general, there are three steps to teach the students in any subject in undergraduate studies must be followed at the universities. After the teacher or the instructor of the course gives some lectures in the subject, the students need to know what reading should be done and what activities should be completed before they come to class discussion or tutorial lectures, after that the instructor gives the tutorial lectures or it can be given by the teaching assistant as well.

A lecture is probably the most standard form of university instructions. Anyone might recognize this from TV shows or movies, it is usually characterized by a large number of students gathering in a large hall sitting and listening to a professor or instructor discuss a particular topic for anywhere from 1-3 hours. Whereas tutorials operate in conjunction with lectures, they usually occur either before or after the lecture with smaller groups of students working with a teaching assistant. In tutorial lectures, students have the opportunity to engage with the course material more directly than they do in the lectures. They have the opportunity to ask questions and discuss the importance and the significance of the readings to the course objectives. Tutorial lectures generally last anywhere from 1-2 hours depending on the class.

The lecturer and the teaching assistant should be sure to let students know ahead of time how they can best prepare for the discussion period in the tutorial lectures. And the students should prepare themselves before they come to the class discussion in the tutorial lecture.

Teaching assistants are often concerned about how to encourage students to attend discussion sections or tutorial lectures. Tutorial participation sometimes is a course requirement or a component of the total student's score, and sometimes it is not, but generally the student's attendance in tutorial lectures does directly influence their course grades [1].

\section{Student's performance evaluation}

To evaluate the performance of the students who attended tutorial lectures and the students who didn't attend any tutorial lecture given by the teaching assistants, there are deferent factors as follows:

\subsection{Percentage of success rate}

In general, the percentage of success rate is a term used in statistics where there are either successes or failures, and it can be calculated as the ratio of the number of students who succeeded the course to the total number of students in the class. It can be expressed as follows:

$$
P S R=\frac{N_{\text {succ. }}}{N_{\text {total }}} \times 100 \%
$$

Where PSR is the percentage of success rate.

$N_{\text {succ. }}$ is the number of students who succeeded the course.

And $N_{\text {total }}$ is the total number of students in the class.

In this study, the number of students who succeeded the course is the number of students who received grades equal to or more than $50 \%$ as it is considering in faculty of engineering at University of Tripoli-Libya.

The opposite of a success rate is the failure rate, and it can be calculated as follows:

$$
\text { PFR }=\frac{N_{\text {failed }}}{N_{\text {total }}} \times 100 \%
$$

Where PFR is the percentage of failure rate.

And $N_{\text {failed }}$ is the number of students who failed in the course. 


\subsection{Mean score value}

The mean score value of the grades for whole students in each class is an important factor to explore the difference between the student's performance in all classes, it can be obtained by dividing the summation of all grades among the whole students by the total number of students in the class. The formula of the mean score value can be expressed as follows:

$$
M S V=\frac{\sum_{i=1}^{i=N_{\text {total }}} G_{i}}{N_{\text {total }}}
$$

Where $M S V$ is the mean score value.

And $G_{i}$ is the student $i$ 's grade.

\subsection{Standard deviation}

The standard deviation is another factor can be used to evaluate the performance of students in each group, and this factor is important in other methods and some statistics to evaluate the student's achievement as it was used previously in [2] and [3].

\subsection{PRNS factor}

In order to evaluate the significant effect of attending tutorial lectures in the nine groups, it can be done by comparing the percentage of the number of students who received marks in each range of the grades to the whole number of students who succeeded the course in the nine groups either with or without tutorial lectures given by a teaching assistant, and it can be expressed as follows:

$$
P R N S=\frac{N_{x}}{N_{\text {succ. }}} \times 100 \%
$$

Where PRNS is the percentage of the number of students who received marks in each range of the grades to the whole number of students who succeeded the course.

And $N_{x}$ is the number of students who received grades in each range.

\section{Data analysis and results}

In this paper, the research study was carried out to examine the influence of the attendance of tutorial lectures given by the teaching assistant on the academic performance of students in undergraduate basic course in Electrical and Electronic Engineering Department, the focus is to determine whether there is any correlation or not in student attendance at tutorial lectures and their achievement.

The data used in this study were taken and collected from the final results of students who completed the "Basic Electronic Circuits" course (EE219) at University of Tripoli-Libya for nine groups in deferent semesters. The student's grades are divided to deferent ranges as illustrated in Table 1 below. Where $N_{50-65}$ is the number of students who achieved total scores in the course equal or more than $50 \%$ and less than $65 \%$ (pass), $N_{65-75}$ is the number of students who received total scores in the course equal or more than $65 \%$ and less than $75 \%$ (credit), $N_{75-85}$ is the number of students who achieved total scores in the course equal or more than $75 \%$ and less than $85 \%$ (distinction), and $N_{>85}$ is the number of students who received total scores equal or more than $85 \%$ (high distinction).

Table 1. The total number of students for the nine groups and the number of students who received marks in each range

\begin{tabular}{|c|c|c|c|c|c|}
\hline & $N_{\text {total }}$ & $N_{50-65}$ & $N_{65-75}$ & $N_{75-85}$ & $N_{>85}$ \\
\hline $\begin{array}{c}\text { Spring 2008 } \\
\text { Group B }\end{array}$ & 58 & 17 & 3 & 0 & 0 \\
$\begin{array}{c}\text { Spring 2009 } \\
\text { Group A }\end{array}$ & 44 & 15 & 1 & 0 & 0 \\
$\begin{array}{c}\text { Spring 2010 } \\
\text { Group B }\end{array}$ & 39 & 9 & 4 & 0 & 0 \\
$\begin{array}{c}\text { Fall 2010 } \\
\text { Group C }\end{array}$ & 50 & 15 & 2 & 0 & 0 \\
$\begin{array}{c}\text { Spring 2012 } \\
\text { Group A }\end{array}$ & 45 & 17 & 0 & 2 & 0 \\
$\begin{array}{c}\text { Spring 2012 } \\
\text { Group B }\end{array}$ & 43 & 8 & 5 & 3 & 0 \\
$\begin{array}{c}\text { Summer } \\
\text { 2012 }\end{array}$ & 22 & 10 & 4 & 1 & 0 \\
$\begin{array}{c}\text { Fall 2012 } \\
\text { Group A }\end{array}$ & 74 & 32 & 6 & 0 & 0 \\
$\begin{array}{c}\text { Fall 2012 } \\
\text { Group B }\end{array}$ & 50 & 22 & 2 & 2 & 2 \\
\hline
\end{tabular}

The class met for two 75-90 minute lectures and one 50-60 minute tutorial per week over a 14-16 week period. Lectures were delivered to the group as a whole and tutorials were held in groups of about 20-30 students. The same lecturer delivered all the lectures, and the same tutor who was not the lecturer, conducted all the tutorials.

Assessment in the course had three components:

1. Homework assignments and quizzes (with a weight of $10 \%$ ).

2. Two mid-term tests ( $20 \%$ each). 
3. And a final examination (with a weight of $50 \%)$.

The homework assignments were given by the lecturer and the teaching assistant as well.

The final examination and mid-term tests were constructed and graded by the lecturer and were based on the theory and the applications that were discussed in the lectures given by the lecturer and tutorial lectures given by the teaching assistant.

Tutorials were used to address student's questions about course content and to review problems and a lot of numerical exercises. There were tutorial quizzes were held at each two tutorial lectures, and its questions were a subset of the numerical problems with slight modifications that were discussed in the tutorials. The teaching assistant constructed and graded the tutorial quizzes, but it is not considered in the final score for the students, it was just to prepare them for the exams and to examine their understanding.

In details, in the five groups with tutorial lectures given by the teaching assistant, all students had equal access to the following learning resources:

1. The subject outline in which topics and the corresponding chapters and sections of the textbook were listed by the lecturer.

2. The textbooks which could be purchased or borrowed from various student resource centers (such as the library). All lecture and tutorial material was consistent with and almost identical to a subset of the content of the textbooks and its study guide, except for some additional exercises on demand elasticity, and a number of new examples given by the teaching assistant.

3. Complete set of hardcopy (word files) of tutorial lectures were prepared and printed by the teaching assistant and given to students with some additional exercises with only the final answers, to make sure that students try to solve those exercises and compare their final answers with the correct answers which given in the sheets.

4. The course group on FACEBOOK provided an open bulletin board, various course resources such as practice questions and some answers, and hyperlinks to useful and interesting sites, and a lot of questions and answers between the students and some discussions with each other, and with the teaching assistant as well.

The only three components of tutorial lectures not directly available to students who missed classes were:

1. Some contemporary topical examples and tutorial quizzes.

2. Discussions arising from in-class student questions and comments given by the teaching assistant.
3. Participation in small in-class exercises and numerical problems.

Finally, students were made aware that the questions on the mid-term test would be based on problems discussed in the tutorial lectures. Students were informed of this verbally, in hardcopy form in the subject outline, and were reminded of this on the FACEBOOK group. Problem sets and review questions for tutorial discussion were made available in class (hardcopy), on the lecturer's and tutor's office doors, and on the FACEBOOK group as well. Tutorial problems and questions were selected from the study guide accompanying the textbook and from end-of-chapter problems and exercises in the textbook and some new problems in the sheets which prepared by the teaching assistant.

Students were encouraged to work together on the problem sets and to post their answers to FACEBOOK group to discuss together. Answers to these problems were presented and discussed in the tutorials. However students who missed a tutorial could visit the lecturer and/or the teaching assistant during scheduled consulting times, or by appointment, to obtain explanations of the answers to problems. It was casually observed by both the lecturer and teaching assistant that the students who made most use of office consultations were those who had high rates of class attendance.

In Table 1, it is clear that the student performance is better with tutorial lectures given by the teaching assistant than those students who didn't have tutorial lectures given by a teaching assistant in their groups. In other words, there is a strong correlation between the range of student's grades and attending tutorial lectures. Students who attended tutorial lectures in Spring 2012 (groups A and B), Summer 2012, and Fall 2012 (groups A and B) tend to perform better than the students who didn't attend tutorial lectures in Spring 2008 (group B), Spring 2009 (group A), Spring 2010 (group B), and Fall 2010 (group C).

It is also obvious that there are some students achieved grades more than $75 \%$ in the groups who attended tutorial lectures given by the teaching assistant in Spring 2012 (groups A and B), Summer 2012, and Fall 2012 (group B), and there are two students achieved scores more than 85\% in Fall 2012 (group B), while in the groups which didn't have tutorial lectures given by a teaching assistant, there is no one received a grade in the range of $75 \%$ to $85 \%$ or more than $85 \%$. Furthermore, six students received grades more than $65 \%$ in Spring 2012 (group B), two of them achieved grades exceeds $85 \%$ which didn't happen in the other 8 groups.

This study was carried out to examine and discover the influence of attendance in tutorial lectures given by the teaching assistant on the performance of undergraduate engineering students at University of Tripoli-Libya. Essentially, the focus 
is to determine whether there is any correlation or not in student's attendance at tutorial lectures and their achievement as follows:

\subsection{Case (1): Student performance without tutorial lectures}

The percentage of the number of students who received grades in each range to the whole number of students who succeeded the course in the four groups without tutorial lectures given by a teaching assistant can be illustrated as in Table 2 .

Table 2. Student performance without tutorial lectures

\begin{tabular}{|c|c|c|c|c|c|}
\hline & $N_{\text {succ. }}$ & $\frac{N_{50-65}}{N_{\text {Succ. }}}$ & $\frac{N_{65-75}}{N_{\text {succ. }}}$ & $\frac{N_{75-85}}{N_{\text {succ. }}}$ & $\frac{N_{>85}}{N_{\text {succ. }}}$ \\
\hline $\begin{array}{c}\text { Spring 2008 } \\
\text { Group B }\end{array}$ & 20 & $85.00 \%$ & $15.00 \%$ & $0 \%$ & $0 \%$ \\
$\begin{array}{c}\text { Spring 2009 } \\
\text { Group A }\end{array}$ & 16 & $93.75 \%$ & $6.25 \%$ & $0 \%$ & $0 \%$ \\
$\begin{array}{c}\text { Spring 2010 } \\
\text { Group B }\end{array}$ & 13 & $69.23 \%$ & $30.77 \%$ & $0 \%$ & $0 \%$ \\
$\begin{array}{c}\text { Fall 2010 } \\
\text { Group C }\end{array}$ & 17 & $88.24 \%$ & $11.76 \%$ & $0 \%$ & $0 \%$ \\
\hline
\end{tabular}

On the other hand, the percentages in Table 2 can be drawn using Log-Linear analysis as shown below in Figure 1.

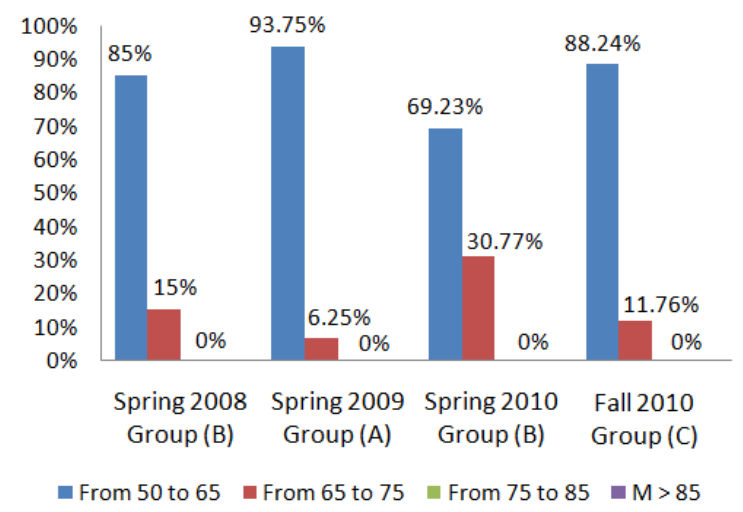

\section{Figure 1. Student performance without tutorial} lectures

From the bar chart of Figure 1, it can be clearly seen that there is no one of the students achieved a grade more than $75 \%$ in the four groups without tutorial lectures given by a teaching assistant.

\subsection{Case (2): Student performance with tutorial lectures}

In this case, the percentage of the number of students who received marks in each range to the whole number of students who succeeded the course in the five groups with tutorial lectures given by the teaching assistant can be illustrated as in Table 3.

Table 3. Student performance with tutorial lectures

\begin{tabular}{|c|c|c|c|c|c|}
\hline & $N_{\text {succ. }}$ & $\frac{N_{50-65}}{N_{\text {succ. }}}$ & $\frac{N_{65-75}}{N_{\text {succ. }}}$ & $\frac{N_{75-85}}{N_{\text {succ. }}}$ & $\frac{N_{>85}}{N_{\text {succ. }}}$ \\
\hline $\begin{array}{c}\text { Spring 2012 } \\
\text { Group A }\end{array}$ & 19 & $89.47 \%$ & $0 \%$ & $10.52 \%$ & $0 \%$ \\
$\begin{array}{c}\text { Spring 2012 } \\
\text { Group B }\end{array}$ & 16 & $50.00 \%$ & $31.25 \%$ & $18.75 \%$ & $0 \%$ \\
$\begin{array}{c}\text { Summer } \\
2012\end{array}$ & 15 & $66.66 \%$ & $26.66 \%$ & $6.66 \%$ & $0 \%$ \\
$\begin{array}{c}\text { Fall 2012 } \\
\text { Group A }\end{array}$ & 38 & $84.21 \%$ & $15.79 \%$ & $0 \%$ & $0 \%$ \\
$\begin{array}{c}\text { Fall 2012 } \\
\text { Group B }\end{array}$ & 28 & $78.57 \%$ & $7.14 \%$ & $7.14 \%$ & $7.14 \%$ \\
\hline
\end{tabular}

And these percentages can be drawn using LogLinear analysis as shown in Figure 2.

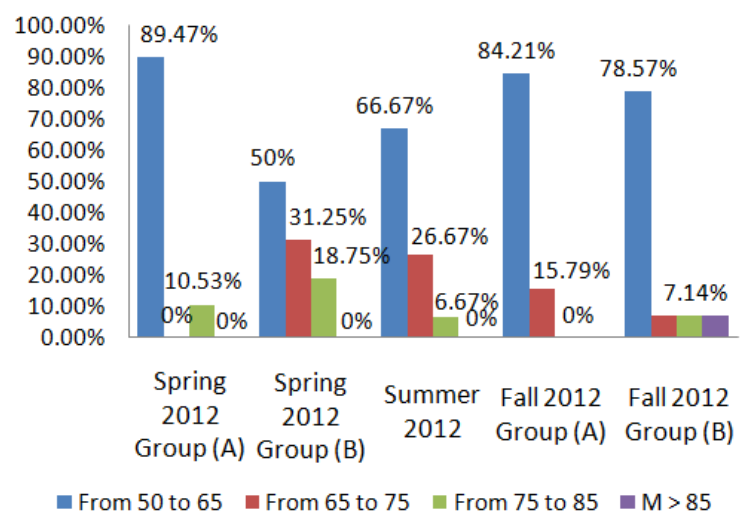

\section{Figure 2. Student performance with tutorial lectures}

The results in this case show that there are significant differences between the performances of students in the classes where the teaching assistant was available compared to the performances of students in the other classes without tutorial lectures given by a teaching assistant.

It can be clearly seen that there are students achieved grades more than $75 \%$ and $85 \%$ with tutorial lectures given by the teaching assistant, but this is however not the only factor to discover the impact of tutorial lectures on the students achievement. So, there are another factors like the 
mean score value and the percentage of success rate for each group.

\subsection{Case (3): The mean score value and the percentage of the success rate}

Table 4 illustrates the mean score value and the percentage of success rate for the nine classes in this study.

Table 4. The mean score and the percentage of the success rate for the nine groups

\begin{tabular}{|c|c|c|c|}
\hline & $N_{\text {total }}$ & $\begin{array}{c}\text { Mean score } \\
\text { value }\end{array}$ & $\begin{array}{c}\text { Percentage of } \\
\text { success rate }\end{array}$ \\
\hline $\begin{array}{c}\text { Spring 2008 } \\
\text { Group B } \\
\text { Spring 2009 } \\
\text { Group A }\end{array}$ & 58 & 40.448 & $34.482 \%$ \\
$\begin{array}{c}\text { Spring 2010 } \\
\text { Group B }\end{array}$ & 39 & 39.307 & $33.333 \%$ \\
$\begin{array}{c}\text { Fall 2010 } \\
\text { Group C }\end{array}$ & 50 & 39.420 & $34.000 \%$ \\
$\begin{array}{c}\text { Spring 2012 } \\
\text { Group A }\end{array}$ & 45 & 38.888 & $42.222 \%$ \\
$\begin{array}{c}\text { Spring 2012 } \\
\text { Group B } \\
\text { Summer } \\
2012\end{array}$ & 43 & 40.837 & $37.209 \%$ \\
$\begin{array}{c}\text { Fall 2012 } \\
\text { Group A }\end{array}$ & 74 & 45.020 & $51.351 \%$ \\
$\begin{array}{c}\text { Fall 2012 } \\
\text { Group B }\end{array}$ & 50 & 45.260 & $56.000 \%$ \\
\hline
\end{tabular}

It is obvious that the mean score value in Spring 2012 (group B), Summer 2012, and Fall 2012 (groups A and B) is better than the mean score value of the other groups. It is clear also that the percentage of the success rate in Spring 2012 (groups A and B), Summer 2012, and Fall 2012 (groups A and $\mathrm{B}$ ) is better than the percentage of the success rate of the other groups without tutorial lectures given by a teaching assistant. This means that the student performance with tutorial lectures given by the teaching assistant is really better than the student performance without tutorial lectures.

It is also obvious that the performance of the students in Spring 2012 (group A and B) is not as good as in both Summer 2012 and Fall 2012 (groups A and B), that's because the teaching skills for the teaching assistant became better than the first time in teaching the tutorial lectures in Spring 2012 (groups $\mathrm{A}$ and $\mathrm{B}$ ).
Figure 3 shown below represents the demographic data concerning the mean value of the grades versus the total number of students in the four groups without tutorial lectures.

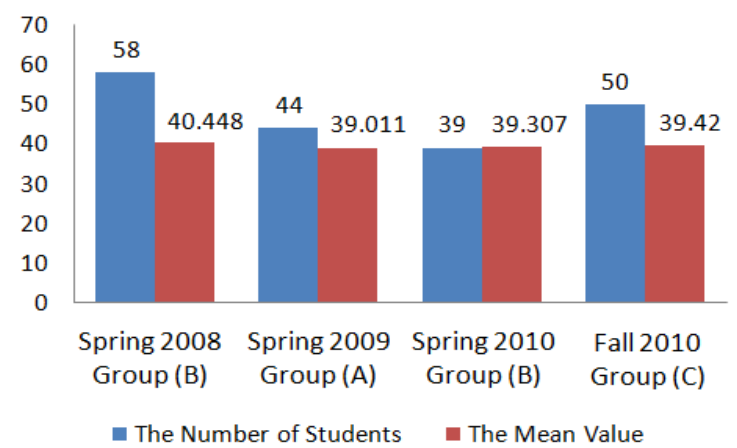

Figure 3. The mean score value versus the total number of students in groups without tutorial lectures

Figure 4 shown below illustrates the demographic data concerning the mean value of the grades versus the total number of students in the five groups with tutorial lectures given by the teaching assistant.

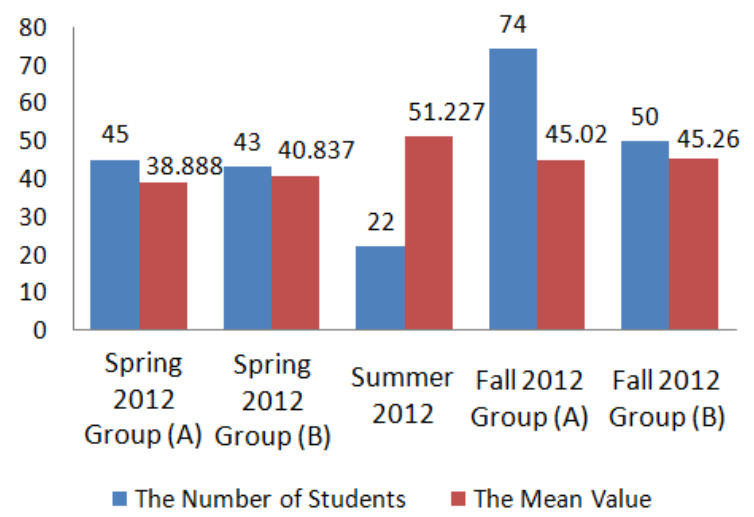

Figure 4. The mean score value versus the total number of students in groups with tutorial lectures

It is evident that there is no significant difference in the mean score value for the four groups with deferent number of students in each group, whereas it is obvious that the mean score value in those semesters with tutorial lectures given by the teaching assistant [Spring 2012 (groups B), Summer 2012, and Fall 2012 (groups A and B)] was better than the mean score value of the student grades in the groups which didn't have tutorial lectures [Spring 2008 (group B), Spring 2009 (group A), Spring 2010 (group B) and Fall 2010 (group C)]. This means that there is an observable improvement in the student's performance with tutorial lectures given by the teaching assistant. 


\subsection{Case (4): Student performance versus the number of students in the class}

Since the performance of the students in both Summer 2012 and Fall 2012 (groups A and B) is better than in the other groups, one can compare the mean score values and the percentage of success and failed rates versus the number of students in these groups as in Table 5 below.

Table 5. The mean score and the percentages of success and failed rates for the nine groups

\begin{tabular}{|c|c|c|c|c|}
\hline & $N_{\text {total }}$ & $\begin{array}{c}\text { Mean } \\
\text { score } \\
\text { value }\end{array}$ & $\begin{array}{c}\text { Percentage } \\
\text { of success } \\
\text { rate }\end{array}$ & $\begin{array}{c}\text { Percentage } \\
\text { of failed } \\
\text { rate }\end{array}$ \\
\hline $\begin{array}{c}\text { Summer } \\
2012\end{array}$ & 22 & 51.227 & $68.181 \%$ & $31.820 \%$ \\
$\begin{array}{c}\text { Fall 2012 } \\
\text { Group A } \\
\text { Fall 2012 } \\
\text { Group B }\end{array}$ & 50 & 45.260 & $56.000 \%$ & $44.000 \%$ \\
\hline
\end{tabular}

Figure 5 shown below represents the demographic data concerning the number of students in the three groups as measured by the percentages of the number of succeeded and failed students and the whole number of the students in each group.

\section{[22 students] [74 students] [50 students]}

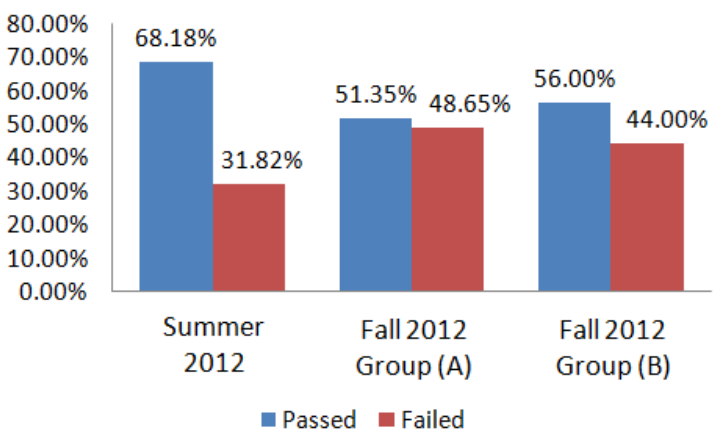

Figure 5. Student performance versus the number of students

\section{Influence of gender and tutorial lectures on academic performance}

Table 6 shows the number of males and females who achieved grades in each range in the nine groups.

Table 6. Influence of gender and tutorial lectures on student's academic achievement

\begin{tabular}{|c|c|c|c|c|c|c|c|c|}
\hline & \multicolumn{2}{|c|}{$N_{50-65}$} & \multicolumn{2}{|c|}{$N_{65-75}$} & \multicolumn{2}{|c|}{$N_{75-85}$} & \multicolumn{2}{|c|}{$N_{>85}$} \\
\hline Gender & $\mathrm{F}$ & $\mathrm{M}$ & $\mathrm{F}$ & $\mathrm{M}$ & $\mathrm{F}$ & $\mathrm{M}$ & $\mathrm{F}$ & $\mathrm{M}$ \\
\hline
\end{tabular}

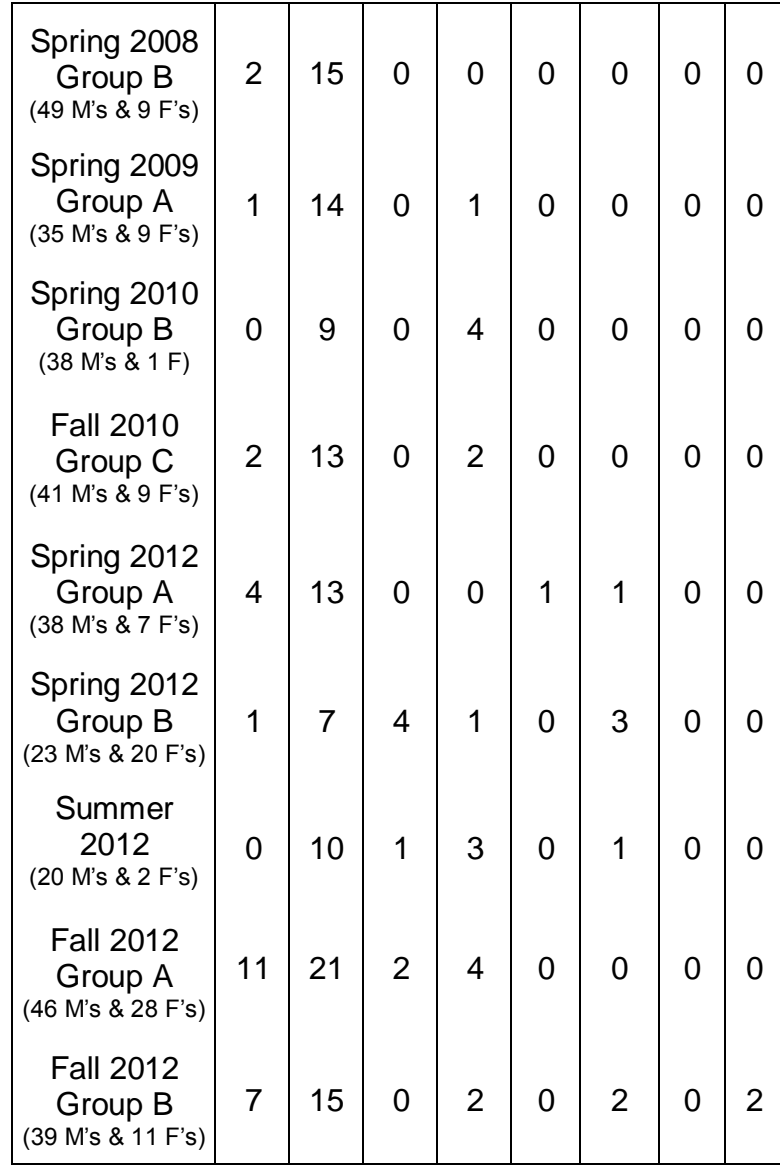

The results in Table 6 indicate that the gender has a significant effect on the student's performance, and male students performing better than their female counterparts. The analysis in this table was done to examine the interaction as well as main effects of gender and tutorial lectures on student's achievement.

Although the difference in the number of male and female students is different, it is clear that male students achieved higher grades than female students as in Fall 2012 (group B). Six male students received grades more than $65 \%$, two of them achieved grades exceeds $85 \%$ which didn't happen in the other 8 groups. So, it is obvious that male students performed better than their female counterparts.

In additions, although there were 20 female students and 23 male students in Spring 2012 (group B) and 4 female students received grades between $65 \%$ and $75 \%$, there were 3 male students achieved grades more than $75 \%$, and the correlation between the gender of students and their performance can be discovered by the high grades. So, male students performed better than female students. 


\section{Discussion of results and future directions}

The main purpose of this study is to examine the impact of tutorial lectures given by the teaching assistant on the performance of undergraduate engineering students, and it was observed from the findings that the attendance of tutorial lectures is a mediating factor in student's performance in a basic undergraduate engineering courses.

The students who attended tutorial lectures in Spring 2012 (groups A and B), Summer 2012 and Fall 2012 (groups A and B) tend to perform better than the students who didn't attend tutorial lectures in Spring 2008 (group B), Spring 2009 (group A), Spring 2010 (group B), and Fall 2010 (group C).

In the four groups without tutorial lectures (from Spring 2008 to Fall 2010), it was found that there is no one of the students achieved a grade in the range of more than $75 \%$, and the highest grade was $72.5 \%$ in Spring 2008, and the student who achieved this grade became the teaching assistant of this course after he has been graduated. And actually he is the author of this paper.

Examination using Log-Linear analysis in this paper is presented, and it showed that there are eight students received marks between $75 \%$ to $85 \%$ in the mentioned course in Spring 2012 (groups A and B), Summer 2012, and Fall 2012 (group A), and two students achieved marks more than 85\% in Fall 2012 (group B). So, the student's performance with tutorial lectures is better than without tutorial lectures given by a teaching assistant.

The results also illustrated that in Summer 2012 there were 22 students in the class, and the percentage of the succeeded students to the total number of the students in this group was more than in Fall 2012 (groups A and B) which have 74 and 50 students respectively. This means that less number of students in the class gives better performance.

Whereas another focus of this study was on class attendance, however, the gender issue in student's achievement was factored into examine its interactive effects with class attendance. As could be observed from the results, it was reported that student gender has effect on achievement in "Basic Electronic Circuits" course. It is however striking to note here that males rather than females (who are noted for better performance in a verbal related subject) performed better in the course. One major explanation for this is that looking closely at the attendance rates; male students have better attendance record than their female counterparts in this course, hence, their show of better performance. The implications of the findings for appropriate remediation programmes for low attendance students and for further research into the reasons for lower female attendance can be discussed in another studies.
Occasionally, some students may believe that their attendance is not essential since the teaching assistant rather than the professor is in charge. Therefore the teaching assistants may want to devise a way to structure required assignments, projects, presentations, or quizzes and homework into their sections so that section participation will be a part of the final course grade. If students know that the teaching assistant has some responsibility for determining their grades, they may be more likely to attend sections or lectures led by the teaching assistant.

Generally, it is not surprising that tutorial lectures given by teaching assistants aid student learning, that's why some people expend considerable resources to give them. In the future, I will show the above data to the students in the respective courses to motivate more of them to attend tutorial lectures with the teaching assistants especially in basic courses in undergraduate studies. However, the magnitude of the difference in outcome based on tutorial attendance is surprising.

Finally, this study has shown that the student's attendance in tutorial lectures given by teaching assistants is very crucial for a better performance in basic courses for undergraduate engineering studies.

\section{Summary of findings}

It could be observed from the findings that tutorial attendance is a mediating factor in student's performance in a "Basic Electronic Circuits" course. This result confirms some other previous findings on the importance of class and tutorial attendance and student's performance in the universities. Attendance at lectures will be considered more crucial for a subject like "Basic Electronic Circuits" subject, as well as the other basic subjects in the engineering studies.

Perhaps, one major implication of this finding is the need to design a remediation approach that will take care of students with low attendance. As pointed out in literature, this category of students will require a one-on-one approach with the teaching assistants. Ordinarily, this approach may be effective in those institutions where course enrolment is low, whereas in those courses with high student enrolment and inadequate technical facilities, then this approach suffers in implementation. However, as much as possible low attendance students could be assisted with more tutorial lessons by teaching assistants, where this is practicable.

The gender issue in student's performance was studied into examine its interactive effects with class attendance, and it was reported that student gender has effect on achievement in "Basic Electronic Circuits" course. It was clear that males performed better than females in the course. In this regard, class attendance cannot be isolated from student gender. 
More male students attend classes regularly and they also record a higher performance in the final grade.

In conclusion, this study has shown that tutorial attendance is very crucial for a better performance in a basic subject like "Basic Electronic Circuits". It has further shown that gender factor is also crucial in analyzing class attendance problem and eventual student achievement in basic courses.

\section{The teaching assistant feedback}

The teaching assistant who gave the tutorial lectures in the mentioned course is the author of this paper, and he said that:

"I was surprised by the results in Spring 2012 when some students achieved grades more than $75 \%$, and the main reason of this improvement was the tutorial lectures which I had tough, and the friendship which I had made with the students, as well as the difference between the age between us. On the other side, I definitely think for those students that become complacent and stop attending early on, it's a good way to keep them focused, attending and completing some questions relating to the course material. Anything making students do some work can only be positive. So taking that into account I think they definitely learnt more than they usually would have done, when they otherwise would have just waited till the week or the day before the test and realized that in fact the material is rather difficult. Obviously, those students have difficulty understanding the material in one few days before the exam. Whereas, for the top students I think it really doesn't make much difference to their learning, but tutorials are not really focused at this group anyway. In addition, students seem to be slightly aware that someone is going to have to mark their work and I did witness some students think about how they lay it out and are aware they will lose marks for insufficient working. So hopefully this ended in them constructing better answers in tests and exams."

\section{Recommendations on tutorial lectures}

This section looks at effective ways of preparing for lectures and tutorial lectures. Lectures are a key feature of university teaching. In broad terms, the principal purpose of a lecture is to provide the students with information in an efficient, wellstructured way. More particularly, lectures:

- Present information and research on specific topics.

- Highlight areas of importance and interest within the topic.

- Work through some of the areas students are likely to find confusing.
- Suggest sources of further information; provide references and how to find them.

But the tutorials are meetings of smaller groups of students to discuss specific topics related to the subject matter of the course. The key focus of tutorial groups is the interactive, participatory nature of the discussion. Tutorial discussions rely for their success on what they do before and during a tutorial. The role of the tutor is to facilitate and encourage the exploration of the relevant issues and problems.

Students should take into consideration some steps to fortify their studying skills as follows:

\subsection{Before the tutorial}

Students have to study and read the required articles or chapters as set out for the tutorial topic in their subject guide.

They have to think about the topic and formulate some basic ideas that they can contribute to the tutorial discussion about the topic.

\subsection{During the tutorial}

They must listen to other tutorial participants and contribute their ideas to the discussion, and ask questions. They don't have to leave the tutorial feeling confused.

\subsection{After the tutorial}

They must write down any notes of comments or ideas that they think are important to remember, and add these to their other subject notes.

But like lectures and tutorials, it is important that they are on time for the class and complete any reading or other tasks that they have been asked to do before the class begins.

\section{Conclusions}

Based on the results of this research, the descriptive statistics show that the student's grades in those semesters where a teaching assistant was available outperform the student grades for the semesters where a teaching assistant was not available. And the analysis of the resulting data reveals a strong correlation between student's grades and attending tutorial lectures given by the teaching assistant. The students who attended tutorial lectures with the teaching assistant in Spring 2012 (groups A and B), Summer 2012 and Fall 2012 (groups A and B) tend to perform better than the students who didn't attend tutorial lectures in Spring 2008 (group B), Spring 2009 (group A), Spring 2010 (group B), and Sall 2010 (group C). Also it was observed that students' performance was inversely proportional to 
the total number of students in the class. And in general, it was clear that male students performed better than females in the mentioned course.

\section{Acknowledgements}

First and foremost, the author would like to thank all his family members for their continued support. He would also like to express his deep appreciation and sincere gratitude to Assoc. Prof. Mustafa M. Abdalla for his motivations and continuous guidance throughout teaching the course "Basic Electronic Circuits". And he gratefully acknowledges the helpful comments and support he has received from both Prof. Hosin Sijiuk and Prof. Abdulkader S. Akki.

\section{References}

[1] Allyson Hadwin, and Susan Wilcox, A Handbook for Teaching Assistants, Instructional Development Centre, Queen's University, Kingston, Ontario, 1999-2000.

[2] Shamsi S. Bawaneh, "Does using computer technology improve students' performance? Evidence from a management accounting course", IJBSS, Centre for Promoting Ideas, USA, Vol. 2 No. 10; June 2011, pp. 266274.

[3] Ramesha, M. Narayanaswamy, "The Effect of Group Tutorials Teaching Strategy of Achievement in Mathematics of Ninth Standard Studentscle Title", Indian journal of research, India, December 2012, pp. 53-54. 